\title{
Experimental Studies on the Influence of $\mathrm{HCO}_{3}{ }^{-}$on Absorption and Desorption of $\mathrm{CO}_{2}$ from Ammonia Solution
}

\author{
Shaojian Jiang, Wei Zhong, Rui Peng, Yong Jiang, Jun Zhang \\ School of Energy Science and Engineering, Central South University, Changsha, China \\ Received 2012
}

\begin{abstract}
With aqueous ammonia in the process of $\mathrm{CO}_{2}$ absorption and desorption to join sodium bicarbonate, the influence of $\mathrm{HCO}_{3}{ }^{-}$on $\mathrm{CO}_{2}$ absorption and desorption from ammonia solution was investigated through the experimental analysis of the desorption quantity of $\mathrm{CO}_{2}$, desorption rate, $\mathrm{CO}_{2}$ loading and the absorption rate. The experimental results showed that, in experimental conditions, The desorption rate decreased gradually with increasing ammonia concentrations. The desorption rate increased $12 \%, 17 \%$, $19 \%$ and $28.8 \%$ when $1 \mathrm{~mol} / \mathrm{L}$ of ammonia solution is added in $0.1 \mathrm{~mol} / \mathrm{L}, 0.3 \mathrm{~mol} / \mathrm{L}, 0.5 \mathrm{~mol} / \mathrm{L}$ and $1 \mathrm{~mol} / \mathrm{L}$ of sodium bicarbonate. The higher concentration of ammonium bicarbonate solution which was added sodium bicarbonate, the more observably the effect of $\mathrm{CO}_{2}$ desorption was promoted. The absorption rate had dropped when absorption process added 0.3 mol/L sodium bicarbonate, the $\mathrm{CO}_{2}$ loading was a little change.
\end{abstract}

Keywords: Ammonia Desorption; the Desorption Rate; $\mathrm{CO}_{2}$ Absorption; $\mathrm{CO}_{2}$ Loading

\section{Introduction}

As the rapid development of modern industry, a large number of the use of fossil fuels leads to increased $\mathrm{CO}_{2}$ emissions, and $\mathrm{CO}_{2}$ is climate change and the main cause of global warming. Therefore, carbon capture and storage (CCS) projects have been reported[1]. The chemical absorption capture of $\mathrm{CO}_{2}$ has been studied and widely used as a reliable and cost-efficient method for $\mathrm{CO}_{2}$ because of its characteristics such as higher absorption rate, higher $\mathrm{CO}_{2}$ recovery rate, no absorbent degration and lower desorption energy requirement, etc[2]. The traditional chemical absorption methods include alcohol amine solution, alkali solution, aqueous alkanolamine solution, etc. Among them, MEA, as a representative of the alcohol amine is the most traditional absorbent[3], it is used in industry early in the 19 th century. However, because its higher desorption engy, amine degradation by $\mathrm{O}_{2}, \mathrm{SO}_{2}$ in flue gas which induces a high absorbent makeup rate and high equipment corrosion rate[4], on the actual plant there is still a limit used in decarburization. Compared with MEA, aqueous ammonia which has higher $\mathrm{CO}_{2}$ loading capacity (g $\mathrm{CO}_{2}$ absorbed per g absorbent), no corrosion problem, no absorbent degradation problem, lower desorption energy [5,6], and the ability to capture all three major acid gases $\left(\mathrm{SO}_{2}, \mathrm{NO}_{\mathrm{X}}, \mathrm{CO}_{2}\right)$, is becoming a hot research 7].

It has been concluded that the maximum $\mathrm{CO}_{2}$ removal efficiency by $\mathrm{NH}_{3}$ absorbent can achieve $95 \%$ and the major produced from the Aqua Ammonia Process including ammonium bicarbonate and ammonium carbonate etc[8]. Due to the process is reversible, therefore, a way to heat its bicarbonate salts to desorb the solution is used to make sorbent recycling. The process to $\mathrm{CO}_{2}$ desorption which is not desorbed completely has resulted in absorption capacity is reduced. Liu Fang[9] researched the process of $\mathrm{CO}_{2}$ desorption from ammonium bicarbonate, Zeng Qing[10] studied the characteristics of $\mathrm{CO}_{2}$ desorption from Carbonated ammonia solution, which showed that desorption rate was influenced by temperature, $\mathrm{CO}_{2}$ loading. Houping Huang[11] investigated a method to regenerate ammonia so as to allow for the ammonia scrubbing technique to be practical in the capture of $\mathrm{CO}_{2}$ that a weakly basic ion-exchange resin containing amine functional groups is used. How to improve the desorption rate, and in the process of absorption recycling, keep the $\mathrm{CO}_{2}$ loading capacity the same are a key research direction.

Research has shown that[12], with the increasing of the conntration of bicarbonate ions, $\mathrm{CO}_{2}$ is easier to release from the solution. This paper studied the influence of $\mathrm{HCO}_{3}{ }^{-}$(put NaH$\mathrm{CO}_{3}$ into solution as a additives) on $\mathrm{CO}_{2}$ absorption and desorption from ammonia solution which keep the concentration of $\mathrm{NH}_{4}{ }^{+}$the same and change the solution of $\mathrm{HCO}_{3}{ }^{-}$concentraon.

\section{Experiment}

\subsection{Theory}

The desorption reaction of $\mathrm{CO}_{2}$ into ammonia solution can be described as the following equations (1), (2), (3). it is shown the lowest enthalpy of dissociation for $\mathrm{CO}_{2}$ release from (1). Ammonium carbonate can be further dissociated to release more $\mathrm{CO}_{2}$, but at higher cost per mole $\mathrm{CO}_{2}$ desorbed. Therefore, in the process of the most favorable desorption is to transfer ammonium carbonate solution from the absorber and use it as $\mathrm{CO}_{2}$ absorbent, as shown in (7). Moreover, it can reduce the $\mathrm{NH}_{3}$ escape.

$$
\begin{gathered}
2 \mathrm{NH}_{4} \mathrm{HCO}_{3}(\mathrm{aq}) \Leftrightarrow\left(\mathrm{NH}_{4}\right)_{2} \mathrm{CO}_{3}(\mathrm{aq})+\mathrm{CO}_{2}(\mathrm{~g})+\mathrm{H}_{2} \mathrm{O}(\mathrm{l}) \\
\mathrm{NH}_{4} \mathrm{HCO}_{3}(\mathrm{aq}) \Leftrightarrow \mathrm{NH}_{3}(\mathrm{aq})+\mathrm{CO}_{2}(\mathrm{~g})+\mathrm{H}_{2} \mathrm{O}(\mathrm{l}) \\
\left(\mathrm{NH}_{4}\right)_{2} \mathrm{CO}_{3}(\mathrm{aq}) \Leftrightarrow 2 \mathrm{NH}_{3}(\mathrm{aq})+\mathrm{CO}_{2}(\mathrm{~g})+\mathrm{H}_{2} \mathrm{O}(\mathrm{l})
\end{gathered}
$$

For absorption reaction,it is typical chemical reaction process as following equations (4), (5),(6), (7). 


$$
\begin{gathered}
\mathrm{CO}_{2}+2 \mathrm{NH}_{3} \rightarrow \mathrm{NH}_{2} \mathrm{COONH}_{4} \\
\mathrm{NH}_{2} \mathrm{COONH}_{4}+\mathrm{H}_{2} \mathrm{O} \Leftrightarrow \mathrm{NH}_{3}+\mathrm{NH}_{4} \mathrm{HCO}_{3} \\
\mathrm{NH}_{3}+\mathrm{NH}_{4} \mathrm{HCO}_{3} \Leftrightarrow\left(\mathrm{NH}_{4}\right)_{2} \mathrm{CO}_{3} \\
\left(\mathrm{NH}_{4}\right)_{2} \mathrm{CO}_{3}+\mathrm{CO}_{2}+\mathrm{H}_{2} \mathrm{O} \Leftrightarrow 2 \mathrm{NH}_{4} \mathrm{HCO}_{3}
\end{gathered}
$$

\subsection{The Experiment System}

The experiments were divided into desorption and absorption process. The schematic diagrams for desorption process were represented in Figure 1. It was experimented with ammonium bicarbonate solution preparation simulation of the practical absorbent, through the adjustment of ammonium bicarbonate solution concentration and adding additives way to control simulation absorbent. The desorption solution was controlled the temperature by water-bath pot. $\mathrm{CO}_{2}$ gas was purged the entire system before the start of the experiment.Then the solution was stirred by the magnetic stirrer.The gas was analysed by $\mathrm{CO}_{2}$ Analyzer through a mixture of gases from desorption after pickling bottle and desiccating agent. In the process of desorption, the temperature controlled in $60^{\circ} \mathrm{C} \sim 99^{\circ} \mathrm{C}$. The desorption rate is tested at $99^{\circ} \mathrm{C}$.

The experimental system for studying $\mathrm{CO}_{2}$ absorption is showed in the schematic diagram of Figure 2. The simulated flue gas consisted of 14 vol.\% $\mathrm{CO}_{2}$ and 86 vol.\% Air. The temperature of the gases was $20^{\circ} \mathrm{C}$, and the flow controlled by mess flow controlled which was $80 \mathrm{~m}^{3} / \mathrm{h}$. The temperature of the absorber was controlled in $40 \sim 50^{\circ} \mathrm{C}$, and the flow was $1450 \mathrm{~L} / \mathrm{h}$ (liquid/gas is about $18 \mathrm{~L} / \mathrm{m}^{3}$ ). The pressure of the whole experiment process was close to 1 atmosphere. In the experimental process, flue gas was flowing through absorption tower continuously and absorber was recycling. After the absorption the gas was analysed by $\mathrm{CO}_{2}$ analyzer.

\section{Result and Discussion}

\section{1. $\mathrm{CO}_{2}$ Desorption Characteristics in Ammonium Bicarbonate Solution}

Experiments of $100 \mathrm{~mL}$ ammonium bicarbonate solution was heated which the concentrations were $1 \mathrm{~mol} / \mathrm{L}, 1.5 \mathrm{~mol} / \mathrm{L}$ and 2 $\mathrm{mol} / \mathrm{L}$. From $55^{\circ} \mathrm{C}$ solution had been heated to a constant temperature when water-bath water was boiling. The desorption process was end when $\mathrm{CO}_{2}$ analyzer show flow velocity was zero. Desorption started quickly when the solution was decomposed and a large number of small bubbles were emerged. With the rise of temperature, the bubbles on the surface of liquid level were becoming bigger, and bubbles was rising quickly as well as they burst. Finally, the bubbles become less and less. It was shown that $\mathrm{CO}_{2}$ desorption from the method of ammonia absorber was obvious effective and with good reproducibility.

Typical $\mathrm{CO}_{2}$ desorption curve of Ammonium bicarbonate solution changing with temperature rules was shown in Figure 3. With the rise of temperature, $\mathrm{CO}_{2}$ desorption speeded rapidly, when the temperature reached $85^{\circ} \mathrm{C}, \mathrm{CO}_{2}$ desorption speed was about to the biggest, and the amount of $\mathrm{CO}_{2}$ desorption increased quickly. It was closed to the best desorption temperature of $87.5^{\circ} \mathrm{C}$ which Liu Fang [13] confirmed in the desorption of the ammonia method of absorbent. With the temperature rise further, the concentration of $\mathrm{HCO}_{3}^{-}$reduced gradually so that little $\mathrm{CO}_{2}$ desorbed out, desorption speed was reduced. As the increasing concentration of $\mathrm{HCO}_{3}{ }^{-}$, the higher concentration of desorption solution could desorb more over $\mathrm{CO}_{2}$. The final desorption rates of $1 \mathrm{~mol} / \mathrm{L}, 1.5 \mathrm{~mol} / \mathrm{L}, 2 \mathrm{~mol} / \mathrm{L}$ of ammonium bicarbonate solution were $57 \%, 54 \%$ and $48 \%$, it was shown that the higher the concentration of solution was, $\mathrm{CO}_{2}$ desorption rate gradually reduced. Because the concentration of $\mathrm{HCO}_{3}{ }^{-}$reduced and $\mathrm{CO}_{3}{ }^{2-}$ increased, leading to inhibit the reaction (1).

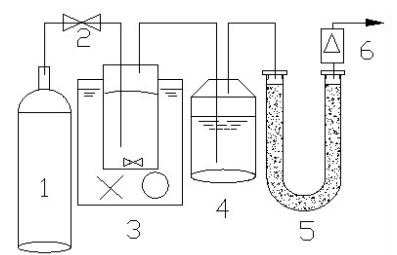

Figure 1. Diagram of the apparatus to measure $\mathrm{CO}_{2}$ desorption from ammonium bicarbonate solution:(1) $\mathrm{CO}_{2}$ Gas,(2) Mass flow controller,(3) Magnetic Stirrer(4) Pickling,(5) Desiccating Agent,(6) $\mathrm{CO}_{2}$ Analyzer.

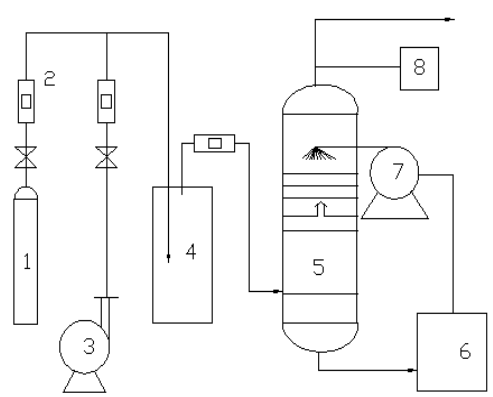

Figure 2. Schematic diagram of experimental setup of $\mathrm{CO}_{2}$ and aqueous ammonia absorption: (1) $\mathrm{CO}_{2}$ Cylinder,(2) Mass Flow Controller, (3) Air compressor, (4)Gas Compound,(5) $\mathrm{CO}_{2}$ Absorber, (6)Reservoir,(7) Pump,(8) $\mathrm{CO}_{2}$ Analyzer.

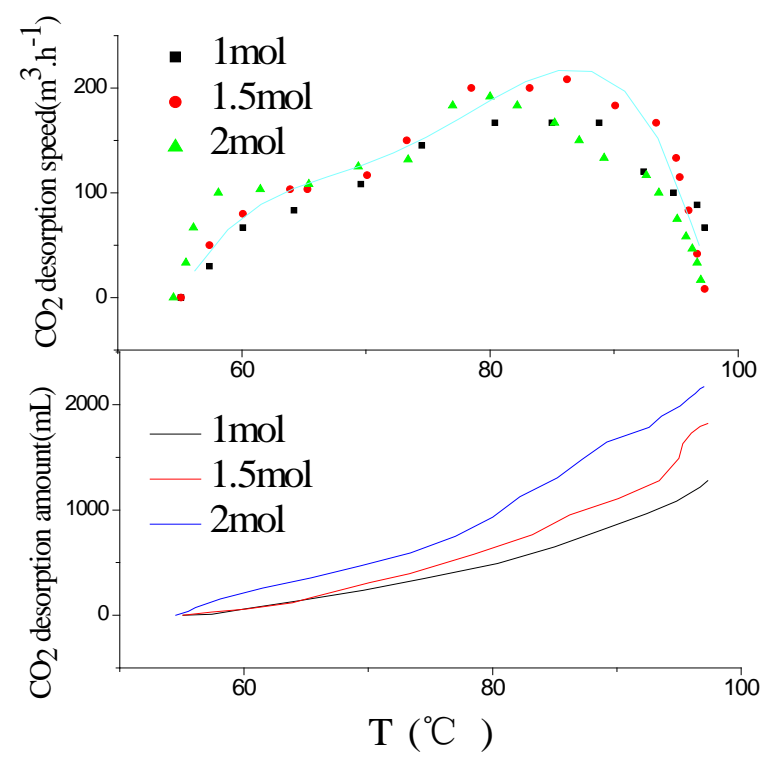

Figure 3. Typical $\mathrm{CO}_{2}$ desorption curve of ammonium bicarbonat. 


\subsection{The Influence on the Desorption of Ammonium Bicarbonate Solution within Sodium Bicarbonate}

The Figure 3 showed the higher the concentration of ammoum bicarbonate solution was, $\mathrm{CO}_{2}$ desorption rate gradually reduced. The following experiments were conducted. Sodium bicarbonate was added into the ammonium bicarbonate solution to change the concentration of $\mathrm{HCO}_{3}{ }^{-}$and ensure $\mathrm{NH}_{4}{ }^{+}$concentration under the condition of invariable, to investigate $\mathrm{HCO}_{3}{ }^{-}$ to the effect of $\mathrm{CO}_{2}$ desorption. $100 \mathrm{~mL}, 1 \mathrm{~mol} / \mathrm{L}$ of ammonium bicarbonate was added $0.1 \mathrm{~mol} / \mathrm{L}, 0.3 \mathrm{~mol} / \mathrm{L}, 0.5 \mathrm{~mol} / \mathrm{L}$ and $1 \mathrm{~mol} / \mathrm{L}$ of sodium bicarbonate to study its $\mathrm{CO}_{2}$ desorption characteristics. The desorption of $1 \mathrm{~mol} / \mathrm{L}$ ammonium bicarbonate solution as a function of sodium bicarbonate concentration was shown in Figure 4.

The $\mathrm{CO}_{2}$ desorption quantity and rate were increased by adding sodium bicarbonate and intensified with higher concentration of sodium bicarbonate.The desorption rate was $58 \%$ for the solution of $1 \mathrm{~mol} / \mathrm{L}$ ammonium bicarbonate solution.The $\mathrm{CO}_{2}$ desorption rate with ammonium bicarbonate solution adding $0,0.1 \mathrm{~mol} / \mathrm{L}, 0.3 \mathrm{~mol} / \mathrm{L}, 0.5 \mathrm{~mol} / \mathrm{L}$ and $1 \mathrm{~mol} / \mathrm{L}$ of sodium bicarbonate solutions were $58 \%, 65 \%, 68 \%, 69 \%$, 74\%, respectively,the efficiencies were increased $12 \%, 17 \%, 19 \%$ and $28.8 \%$. The sodium bicarbonate solutions of $0.1 \sim 0.3 \mathrm{~mol} / \mathrm{L}$ into $1 \mathrm{~mol} / \mathrm{L}$ ammonium bicarbonate solution afforded the greatest rate of increased desorption.Over $0.3 \mathrm{~mol} / \mathrm{L}$ the rate was slow. According to the chemical reaction kinetics, it was supposed to make positive reaction for desorption to make the amount of $\mathrm{CO}_{2}$ desorption increased when the concentration of $\mathrm{HCO}_{3}{ }^{-}$ continued to increase. The higher concentration of sodium bicarbonate which was weakly alkaline salt was,the degree of hydrolysis was more and more small. Meanwhile, it's inhibit effect to the $\mathrm{NH}_{4} \mathrm{HCO}_{3}$ ionization and makes the growth of desorption amount.

\subsection{The Influence of the Desorption of Different Concentration of Ammonium Bicarbonate Solution within Sodium Bicarbonate}

$\mathrm{CO}_{2}$ desorption characteristics for $1 \mathrm{~mol} / \mathrm{L}, 1.5 \mathrm{~mol} / \mathrm{L}, 2 \mathrm{~mol} / \mathrm{L}$, $2.5 \mathrm{~mol} / \mathrm{L}$ of ammonium bicarbonate solution were investigated which was joined $0.3 \mathrm{~mol} / \mathrm{L}$ of sodium bicarbonate. The desorption of different concentration of ammonium bicarbonate solution as a function of sodium bicarbonate concentration was shown in Figure 5. The increasing desorption amount with increasing concentration expressed on approximate linear relationship. Nevertheless, the result that the higher the concentration of solution was, $\mathrm{CO}_{2}$ desorption rate gradually reduced had been confirmed in Figure 3. the quantity of $\mathrm{CO}_{2}$ desorption and the concentration had an inverse proportion relation. When adding sodium bicarbonate, $\mathrm{CO}_{2}$ desorption rate increased and the higher concentration of ammonium bicarbonate solution the better effect of the $\mathrm{CO}_{2}$ desorption rate bringing about by introducing $\mathrm{HCO}_{3}{ }^{-}$, and the speed reduction of desorption rate slowed down. Compared with $1.5 \mathrm{~mol} / \mathrm{L}$,plus $0.3 \mathrm{~mol} / \mathrm{L}$ sodium bicarbonate into $2 \mathrm{~mol} / \mathrm{L}$ of ammonium bicarbonate solution had only declined $3.2 \%$. Add $2 \mathrm{~mol} / \mathrm{L}$ of sodium bicarbonate ammonium bicarbonate solution of the $\mathrm{CO}_{2}$ desorption rate than only $1.5 \mathrm{~mol} / \mathrm{L}$ declined $3.2 \%$. This shown that the higher concentration of absorbent plus sodium bicarbonate, the more ob- servably the effect of $\mathrm{CO}_{2}$ desorption was promoted.

\subsection{Sodium Bicarbonate of $\mathrm{CO}_{2}$ Absorption Effect}

Using ammonia method to absorb $\mathrm{CO}_{2}$, the absorbent circulated after desorption. When plus sodium bicarbonate,it had an inuence on the absorption process.Carbon dioxide absorption rates for $5 \%$ ammonia solution and plus $0.3 \mathrm{~mol} / \mathrm{L}$ sodium bicarbonate were measured in the experiment equipment(Figure 2). For each amine concentration about $\mathrm{CO}_{2}$ loadings were tested. The experimental results were represented in Figure 6. Ammonia solution had an great effect on absorbing $\mathrm{CO}_{2}$, the $\mathrm{CO}_{2}$ absorption capacity reduced with increasing $\mathrm{CO}_{2}$ loading. When added sodium bicarbonate, the absorption rate decreased.

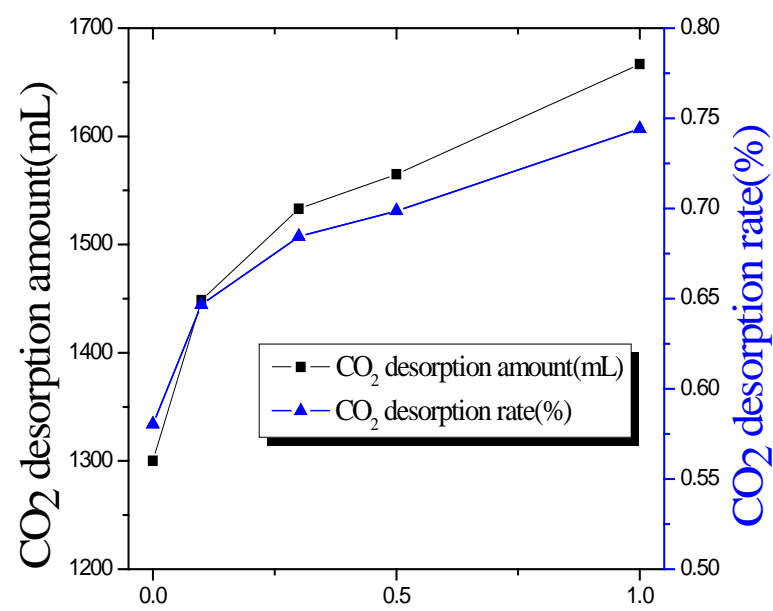

the concentration of sodium bicarbonate(mol/L)

Figure 4. The desorption of ammonium bicarbonate solution as a function of sodium bicarbonate concentration.

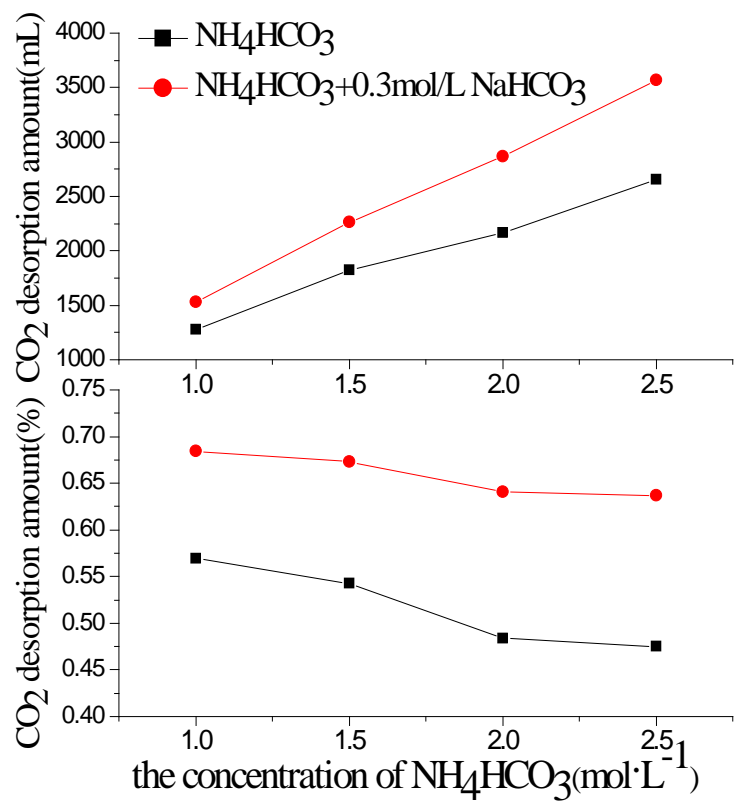

Figure 5. The desorption of different concentration of ammonium bicarbonate solution as a function of sodium bicarbonate concentration. 


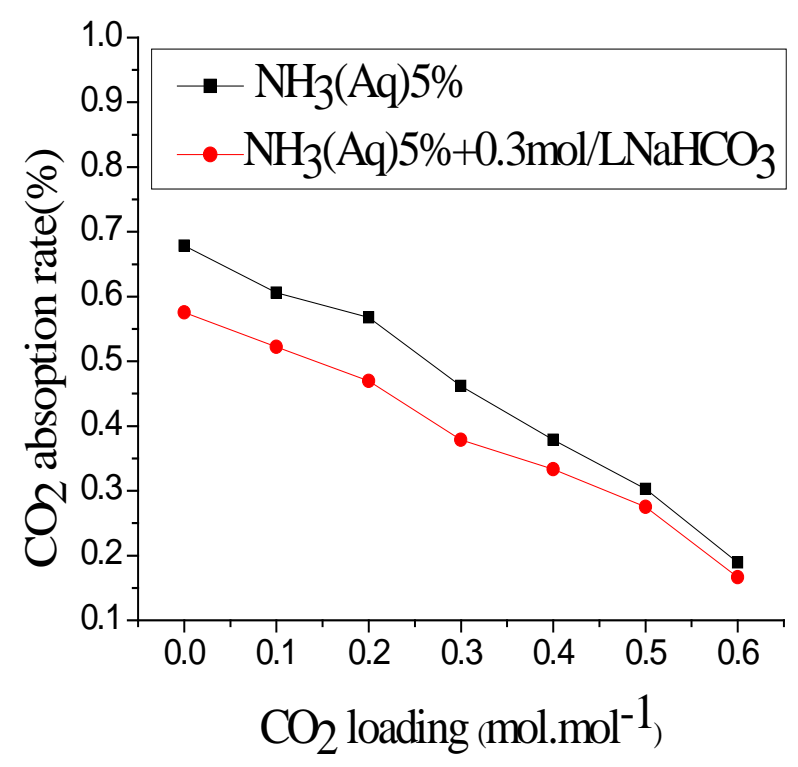

Figure 6. $\mathrm{CO}_{2}$ removal efficiency lines in aqueous ammonia and aqueous ammonia within sodium bicarbonate.

There was so much free ammonia in low $\mathrm{CO}_{2}$ loading in the early stage that carbamate $\left(\mathrm{NH}_{2} \mathrm{COO}^{-}\right)$was the main species[14]. Meanwhile, the concentration of carbamate increased with increasing $\mathrm{CO}_{2}$ loading. Moreover, Carbamate and carbonate ions would be gradually converted to bicarbonate ions as increasing absorbed amount of $\mathrm{CO}_{2}$ in ammonia solution(Eq. 5) after a certain time. The process was inhibited by adding sodium bicarbonate and leading to the drop of the $\mathrm{CO}_{2}$ absorption rate. While by changing the operation conditions, as well as the absorption tower structure could be improved the absorption rate.

Along with the absorption process, the absorption rate reduced gradually with increasing $\mathrm{CO}_{2}$ loading, and the $\mathrm{CO}_{2}$ loading capacity reduced when added sodium bicarbonate, but the speed reduction of $\mathrm{CO}_{2}$ loading slowed down.Respectively, the concentration of free ammonia decreased rapidly, while the speed reduction of that slowed down. The concentration of $\mathrm{NH}_{4}{ }^{+}$remained the same in whole solution, for the same absorption effect, $\mathrm{CO}_{2}$ loading changed a little.

\section{Conclusion}

1) Using ammonia method had an good effect on $\mathrm{CO}_{2}$ absorption and desorption. High concentration of absorbent could also have lower rates of desorption.

2) Sodium bicarbonate as additives, could greatly improve the $\mathrm{CO}_{2}$ desorption rate, with the increasing of the concentration of $\mathrm{HCO}_{3}^{-}$, the speed reduction of $\mathrm{CO}_{2}$ desorption rate slowed down.

3) For different concentration of absorbent, the higher concentration of absorbent plus sodium bicarbonate,the more observably the effect of $\mathrm{CO}_{2}$ desorption was promoted.

The absorption process joined sodium bicarbonate, the absorption rate had reduced, $\mathrm{CO}_{2}$ loading changed a little.

\section{REFERENCES}

[1] STEENEVELDT R, BERGER B, TORP T A. $\mathrm{CO}_{2}$ CAPTURE AND STORAGE Closing the Knowing-Doing Gap[J]. Chemical Engineering Research and Design, 2006, 84:739-763.

[2] Choi W J, Min B M, Shon B H, Seo J B, Oh K J. Characteristics of absorption/regeneration of $\mathrm{CO} 2-\mathrm{SO} 2$ binary systems into aqueous AMP + ammonia solutions[J]. Journal of Industrial and Engineering Chemistry, 2009, 15:635-640.

[3] Jassim M S, Rochelle G, Eimer D, Ramshaw C. Carbon Dioxide Absorption and Desorption in Aqueous Monoethanolamine Solutions in a Rotating Packed Bed[J]. American Chemical Society,2007, 46:2823-2833.

[4] Yeh A C, Bai H. Comparison of ammonia and monoethanolamine solvents to reduce $\mathrm{CO}_{2}$ greenhouse gas emmisions[J]. The Science of the Total Environment, 1999,228:121-133

[5] Puxty G, Rowland R, Attalla M. Comparison of the rate of $\mathrm{CO}_{2}$ absorption into aqueous ammonia and monoethanolamine[J]. Chemical Engineering Science, 2010, 65:915-922.

[6] DIAO Yong-fa, ZHENG Xian-yu, HE Bo-shu, Chen Chang-he, $\mathrm{Xu} \mathrm{Xu}$-chang. Experimental study on capturing $\mathrm{CO}_{2}$ greenhouse gas by ammonia scrubbing[J]. Energy Conversion and Management, 2004,45:2283-2296.

[7] Resink K P, Yeh J T, Pennline H W. Aqua ammonia process for simultaneous removal of $\mathrm{CO}_{2}, \mathrm{SO}_{2}$ and $\mathrm{NO}_{\mathrm{x}}[\mathrm{J}]$. Int. J. Environ Technol Manag, 2004,4(1/2):89-104

[8] Mani F, Peruzzini M, Stoppioni P. $\mathrm{CO}_{2}$ absorption by aqueous $\mathrm{NH}_{3}$ solutions: speciation of ammoniumcarbamate, bicarbonate and carbonate by a ${ }^{13} \mathrm{C}$ NMR study[J]. Green Chemistry, 2006, 8:995-1000.

[9] Liu Fang, WANG Shu-juan, ZHANG Xi, Sun Xin-yu, Chen Chang-he, $\mathrm{Xu} \mathrm{Xu-chang.} \mathrm{Study} \mathrm{on} \mathrm{ammonium} \mathrm{bicarbonate} \mathrm{de-}$ composition after $\mathrm{CO}_{2}$ sequestration by ammonia method [J]. Acta Scientiae Circumstantiae ,2009,29(9):1886-1890.(in Chinese)

[10] Zeng Qing, Guo Yin-cheng, Niu Zhen-qi, Lin Wen-xi. Experimental Studies on Carbon Dioxide Desorption from Carbonated Ammonia Solution in a Packed Column. //Third International Conference on Measuring Technology and Mechatronics Automation, 2011.

[11] Huang H, Chang S G. Method to Regenerate Ammonia for the Capture of Carbon Dioxide[J]. Energy \& Fuels, 2002, 16:904-910.

[12] Liu Fang, WANG Shu-juan, Chen Chang-he, Xu Xu-chang. Research progress of $\mathrm{CO} 2$ capture by using ammonia from flue gas of power plant[J]. CIESC Journal, 2009, 60:269-278. (in Chinese)

[13] Yeh J T, Resnik K P, Rygle K, Pennline H W. Semi-batch absorption and regeneration studies for $\mathrm{CO}_{2}$ capture by aqueous ammonia[J]. Fuel Processing Technology, 2005, 86:1533-1546.

[14] Bai H, Yeh A C. Removal of CO2 Greenhouse Gas by Ammonia Scrubbing[J]. American Chemical Society,1997, 36:2490-2493.

[15] Liu Fang. Experimental Study on $\mathrm{CO}_{2}$ Capture from Flue Gas of Coal-Fired Power Plant by Regenerated Aqua Ammonia[D]. Power Engineering and Engineering Thermophysics. Tsinghua University, 2009, 102-103. (in Chinese)

[16] Ahn C K , Lee H W, Lee M W,Chang Y S, Han K, Rhee C H, Kim J Y, Chun H D, Park J M. Determination of Ammonium Salt/Ion Speciation in the $\mathrm{CO}_{2}$ Absorption Process Using Ammonia Solution: Modeling and Experimental Approaches[J]. Energy Procedia, 2011, 4:541-547. 